\title{
Laparoscopic Beger procedure for the treatment of chronic pancreatitis: a single- centre first experience
}

\author{
He Cai ${ }^{1,2}$, Yunqiang Cai ${ }^{1,2}$, Xin Wang ${ }^{1}$ and Bing Peng ${ }^{1 *}$
}

\begin{abstract}
Background: The Beger procedure is a common surgical option in the management of the unremitting abdominal pain of chronic pancreatitis (CP). As an organ-sparing surgery, it might be a better choice than pancreatoduodenectomy (PD). However, it is rather challenging for surgeons to perform the Beger procedure laparoscopically, especially for patients with CP; indeed, it has rarely reported. Here, we describe the technique and results of our early experience in laparoscopic Beger procedure for the treatment of CP.

Case presentation: Five patients ( 1 male) with CP (alcohol induced, $n=3$; idiopathic, $n=2$ ) who underwent laparoscopic Beger procedure from May to October 2019 in West China Hospital were included in this study. The median pancreatic duct diameter was 6.8 (4 to 12) mm. The median operating time was 275 (150 to 305) minutes without conversion. Only one patient (20\%) developed a grade B pancreatic fistula. One patient required reoperation for jejunal anastomotic bleeding on the first post-operative day. The median hospital stay was 11 (9 to 34) days. No patient experienced biliary fistula, gastroparesis, duodenal necrosis, or abdominal bleeding. The 90-day mortality rate was $0 \%$. All the patients were pain free in the two months after the operation.
\end{abstract}

Conclusion: The laparoscopic Beger procedure is feasible and safe with good short-term results and some potential benefits in selected patients with chronic pancreatitis. Further study and longer follow-up are required.

Keywords: Laparoscopic, Beger procedure, Chronic pancreatitis

\section{Background}

Chronic pancreatitis $(\mathrm{CP})$ is a recurrent fibro-inflammatory disease of the exocrine pancreas leading to permanent structural impairment of the parenchyma [1]. Patients with $\mathrm{CP}$ mostly present with inflammatory pancreatic head enlargement, with possible development of local complications such as intractable pain, stenosis of the pancreatic or bile duct, large and numerous pancreatic stones, or compression of retro-pancreatic vessels [2]. In those patients, the need for surgical intervention is greater than the need for endoscopic treatment, which has

\footnotetext{
*Correspondence: 3613761524@qq.com

1 Department of Pancreatic Surgery, West China Hospital, Sichuan University, No. 37, Guo Xue Xiang, Chengdu 610041, Sichuan, China

Full list of author information is available at the end of the article
}

been proven in randomized controlled trials to especially address pain relief [3-5].

Surgery for chronic pancreatitis can be broadly categorized into drainage or resection procedures [6]. The Beger procedure is a combined drainage and resection technique that was first introduced by Beger and colleagues for CP in the early 1970s [7]. The idea was that a subtotal resection of the pancreatic head might eliminate complications related to the inflammatory head mass, while preserving the duodenum, bile duct, normal enteric passage, interaction of duodenal hormones and insulin secretion [8]. With the development of minimally invasive surgery, this approach can provide several advantages over open surgery, such as fewer complications and faster recovery. However, performing the Beger

(c) The Author(s). 2020 Open Access This article is licensed under a Creative Commons Attribution 4.0 International License, which permits use, sharing, adaptation, distribution and reproduction in any medium or format, as long as you give appropriate credit to the original author(s) and the source, provide a link to the Creative Commons licence, and indicate if changes were made. The images or other third party material in this article are included in the article's Creative Commons licence, unless indicated otherwise in a credit line to the material. If material is not included in the article's Creative Commons licence and your intended use is not permitted by statutory regulation or exceeds the permitted use, you will need to obtain permission directly from the copyright holder. To view a copy of this licence, visit http://creativecommons.org/licenses/by/4.0/. The Creative Commons Public Domain Dedication waiver (http://creativecommons.org/publicdomain/zero/1.0/) applies to the data made available in this article, unless otherwise stated in a credit line to the data. 
procedure laparoscopically is technically challenging, especially for $\mathrm{CP}$. There are only a few case reports of the minimally invasive Beger procedure for $\mathrm{CP}$ in the literature $[9,10]$. Herein, we report our early experience in laparoscopic Beger procedure for the treatment of $\mathrm{CP}$.

\section{Case presentation}

\section{Patients}

This study was conducted from May to October 2019 in the Department of Pancreatic Surgery of West China Hospital. Five patients ( 1 male, 4 females, median age 52 years, range $29-73$ years) with an established diagnosis of $\mathrm{CP}$ who underwent laparoscopic Beger procedure were included in the study (Table 1). The preoperative symptoms included repeated abdominal pain (5 cases), pancreatic duct stones (4 cases), diarrhoea (1 case) and weight loss ( 2 cases). The diagnosis was confirmed by enhanced computed tomography scan. The main indication for surgery was pancreatic head enlargement with intractable pain (5 cases), and both medical management and endoscopic interventions fail to provide pain relief. Other indications for operation include obstruction of the common bile duct, pancreatic duct obstruction or stenosis, duodenal obstruction, and/or entrapment of the retroperitoneal superior mesenteric or portal veins. All patients were informed of the surgery, and signed consent forms were obtained from them. The median (range) pancreatic duct diameter were 6.8 (4 to 12$) \mathrm{mm}$. The preoperative details and disease characteristics are shown in Table 1. Pain was assessed by the validated Izbicki [11] pain score, as depicted in Table 2.

\section{Surgical procedures}

The patients were placed in the supine position with the two legs apart. The observing trocar $(10 \mathrm{~mm})$ was located at the inferior umbilicus. Four trocars were distributed symmetrically at the midclavicular line and anterior axillary line. Another 5-mm trocar located at the subxiphoid was used to suspend the stomach. The gastrocolic ligament was opened and the hepatic flexure of the colon was taken down to explore the head of the

Table 1 Preoperative Details and Disease Characteristics

\begin{tabular}{lllll}
\hline Patient & Etiology & Age/Sex & MPDD $(\mathrm{mm})$ & Comorbidities \\
\hline 1 & Idiopathic CP & $29 / \mathrm{F}$ & 9 & $\begin{array}{l}\text { Pancreatic endocrine } \\
\text { insufficiency }\end{array}$ \\
2 & Alcoholic CP & $73 / \mathrm{M}$ & 12 & $\begin{array}{l}\text { Pancreatic endocrine } \\
\text { and exocrine } \\
\text { insufficiency }\end{array}$ \\
3 & Alcoholic CP & $35 / \mathrm{F}$ & 8 & Nil \\
4 & Alcoholic CP & $56 / \mathrm{F}$ & 6 & Nil \\
5 & Idiopathic CP & $52 / \mathrm{F}$ & 4 & Nil \\
\hline
\end{tabular}

$C P$ indicates chronic pancreatitis; $F$ female, $M$ male, MPDD main pancreatic duct diameter
Table 2 Preoperative Pain Score (Total Score: Sum of Single Values Divided by 4)

\begin{tabular}{llllll}
\hline Patient & $\begin{array}{l}\text { Frequency of } \\
\text { pain attacks }\end{array}$ & VAS $^{\mathrm{b}}$ & $\begin{array}{l}\text { Analgetic } \\
\text { medication }\end{array}$ & $\begin{array}{l}\text { Inability to } \\
\text { work }^{\mathrm{d}}\end{array}$ & Total \\
\hline 1 & 75 & 50 & 20 & 50 & 48.75 \\
2 & 50 & 40 & 15 & 25 & 32.5 \\
3 & 100 & 50 & 20 & 75 & 61.25 \\
4 & 50 & 60 & 15 & 50 & 43.75 \\
5 & 75 & 40 & 20 & 50 & 46.25 \\
\hline
\end{tabular}

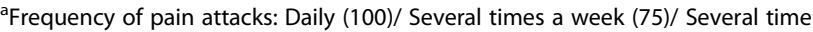
a month (50)/ Several time a year (25)/ None (0)

bVAS (Visual Analog Scale of Pain): (No pain: 0-imaginative maximum of pain: 100)

'Analgetic medication (morphine-related analgetic potency): Morphine (100)/ Buprenorphine (80)/ Pethidine (20)/ Tramadol (15)/ Metamizole (3)/

Acetylsalicylic acid (1)

d Inability to work (last year): Permanent (100)/ $\leq 1$ year $(75) / \leq 1$ month $(50) / \leq 1$ week (25)/ None (0)

pancreas. The right gastroepiploic vein and Henle's trunk were dissected (Fig. 1). The no. 8a lymph node was dissected for intraoperative rapid frozen pathology. The pancreatic neck was transected with an ultrasonic scalpel, and the main pancreatic duct was transected with cold scissors. The superior mesenteric vein (SMV) was retracted to the left. The uncinate process of the pancreas was retracted to the right, and subcapsular dissection was carried out, paying particular attention to protecting the inferior pancreaticoduodenal artery (IPDA) and its branches. Then the gastro-duodenal artery (GDA) was identified and protected (Fig. 2). The anterior superior pancreatic duodenal artery (ASPDA) was dissected. The upper part of the pancreatic head was separated to expose the common bile duct (CBD) (Fig. 3). The pancreas was dissected from the left edge of the duodenum and the right edge and the ventral edge of the CBD (Fig. 4). The posterior superior pancreatic duodenal artery (PSPDA) was identified at the dorsal edge of the CBD. The PSPDA and its branches were carefully preserved. The proximal of main and accessory pancreatic ducts were identified and sutured. Roux-en-Y ductto-mucosa pancreaticojejunostomy was carried out with the left pancreas which was performed using the technique of Bing's anastomosis (Fig. 5) [12]. Two closed drainages were routinely placed behind the pancreaticojejunostomy and near the common bile duct, respectively.

\section{Operative and postoperative outcomes}

The operations were successfully performed for the five patients without conversion. The operative and postoperative outcomes are shown in Table 3 . The operative times varied between 150 and 305 min (median 275 min). Blood loss ranged between 100 and $300 \mathrm{ml}$ (median $200 \mathrm{ml}$ ). Hospital stay varied between 9 and $34 \mathrm{~d}$ (median 11 d). Only one patient (20\%) developed a grade $B$ pancreatic fistula [13] with drainage delayed on the 


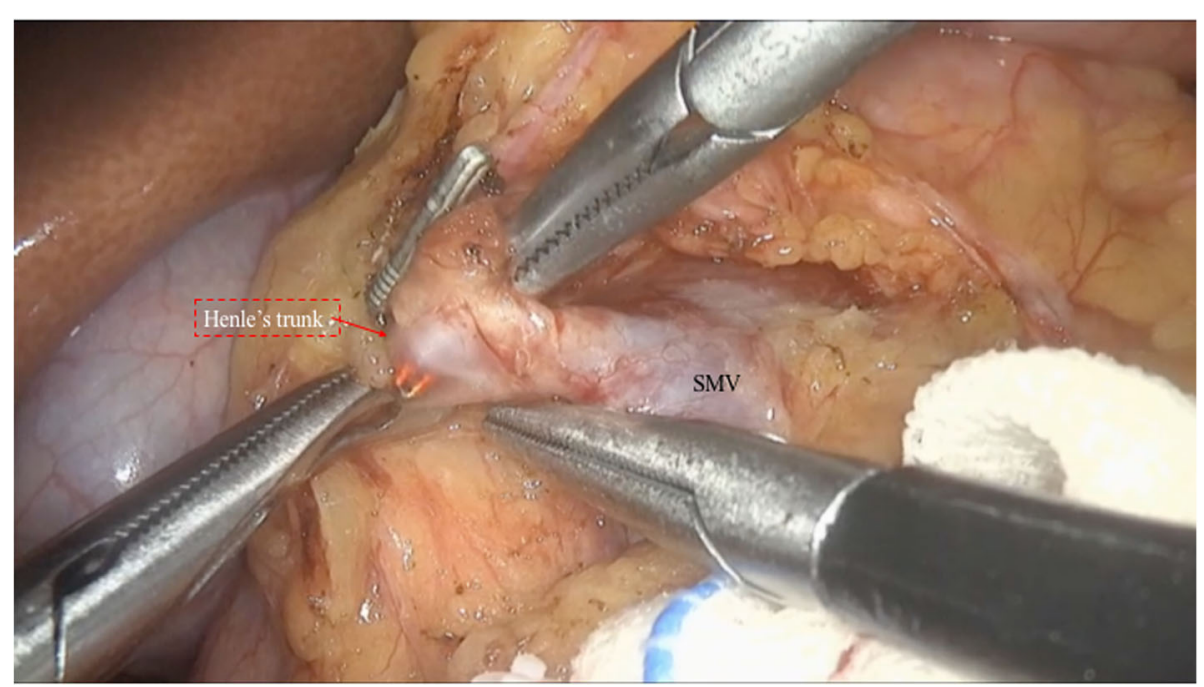

Fig. 1 Dissect the Henle's trunk

thirtieth day after the operation. One patient required reoperation for jejunal anastomotic bleeding on the first postoperative day, she was discharged uneventfully on the tenth day after the second operation. No patient experienced grade $\mathrm{C}$ pancreatic fistula, biliary fistula, gastroparesis, duodenal necrosis, or abdominal bleeding. No mortality had occurred at 90 days after the surgery. All patients were pain free in the two months after the operation. No statistical comparison was performed due to the small sample size.

\section{Discussion and conclusions}

$\mathrm{CP}$ is a complex inflammatory disease involving an enlarged pancreatic head as the main morphologic pathology and pain as the most common symptom [6]. Pain reduction is the main goal of treatment because it is the most important factor that influences a patients' quality of life $[14,15]$. The pain is caused by the obstruction of the pancreatic duct and neuronal alterations in the fibrous converted pancreatic tissue in which the pancreatic head is the pacemaker [16]. Therefore, surgery for $\mathrm{CP}$ can be broadly classified into three categories: drainage procedures, partial pancreatic resection and their combination. The most common drainage procedure is the modified Puestow procedure, also known as lateral pancreatojejunostomy [17]. The first duodenum preserving pancreatic head resection (DPPHR) was introduced by Beger in 1972 and consisted of preserving a thin rim of pancreatic tissue along the duodenal loop and two

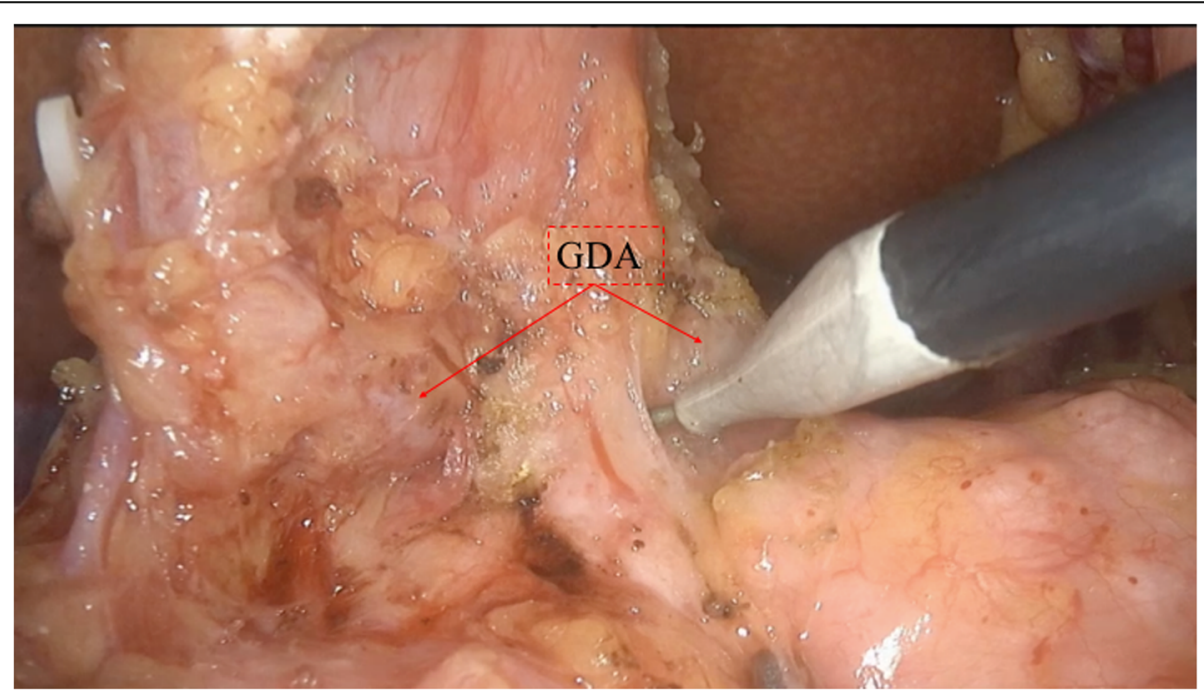

Fig. 2 Identify and protect the GDA 


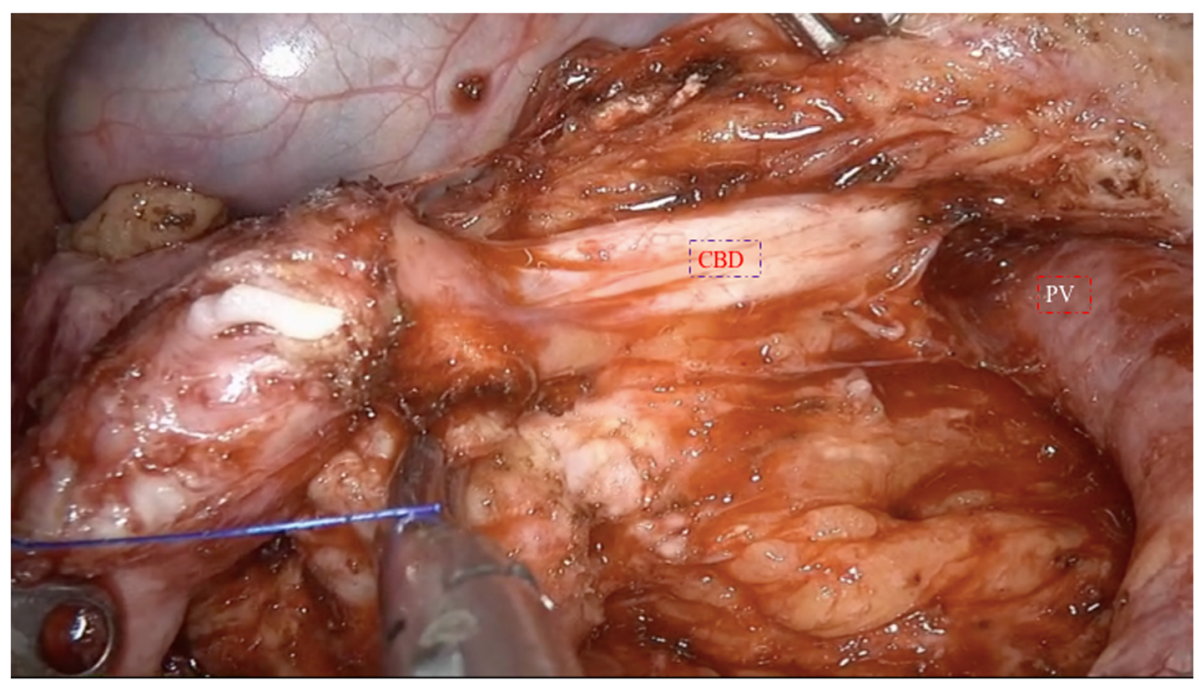

Fig. 3 Identify and protect the CBD

pancreatic anastomoses [7]. Other DPPHR procedures, including the Frey [18] and Berne [19] procedures related to the removal extent of pancreatic tissue or the combination with drainage aspects, have been suggested. For many years, pancreaticoduodenectomy (PD) has been applied as a standard operation in the treatment of CP [15]. Compared to DPPHR, PD is a radical surgery associated with multi-organ resection and may result in endocrine and exocrine dysfunctions of the pancreas. DPPHR is more technically challenging and timeconsuming. Beger procedures should be considered in patients with an enlarged pancreatic head $(>4 \mathrm{~cm})$ [15]. For patients with painful $\mathrm{CP}$, a dilated main pancreatic duct $(>5 \mathrm{~mm})$ and a normal-sized pancreatic head $(<4$ $\mathrm{cm})$, a lateral pancreatojejunostomy and Frey's procedure may be suggested.

In contrast to the classic Beger procedure, we only preserved a small part of pancreatic tissue behind the $\mathrm{CBD}$; therefore, only one pancreatic anastomosis was necessary [7]. Moreover, compared with open surgery, laparoscopic surgery can more clearly show the vascular arcades due to the amplification of the surgical field. We preserved the IPDA and PSPDA; however, we resected the ASPDA, which is also different from the classic Beger procedure [7]. Nonetheless, laparoscopic surgery for $\mathrm{CP}$ is rather challenging with regard to fibrous scarring, and we completed all surgeries successfully without conversion. In an early study, Yin $\mathrm{Z}$ reported better

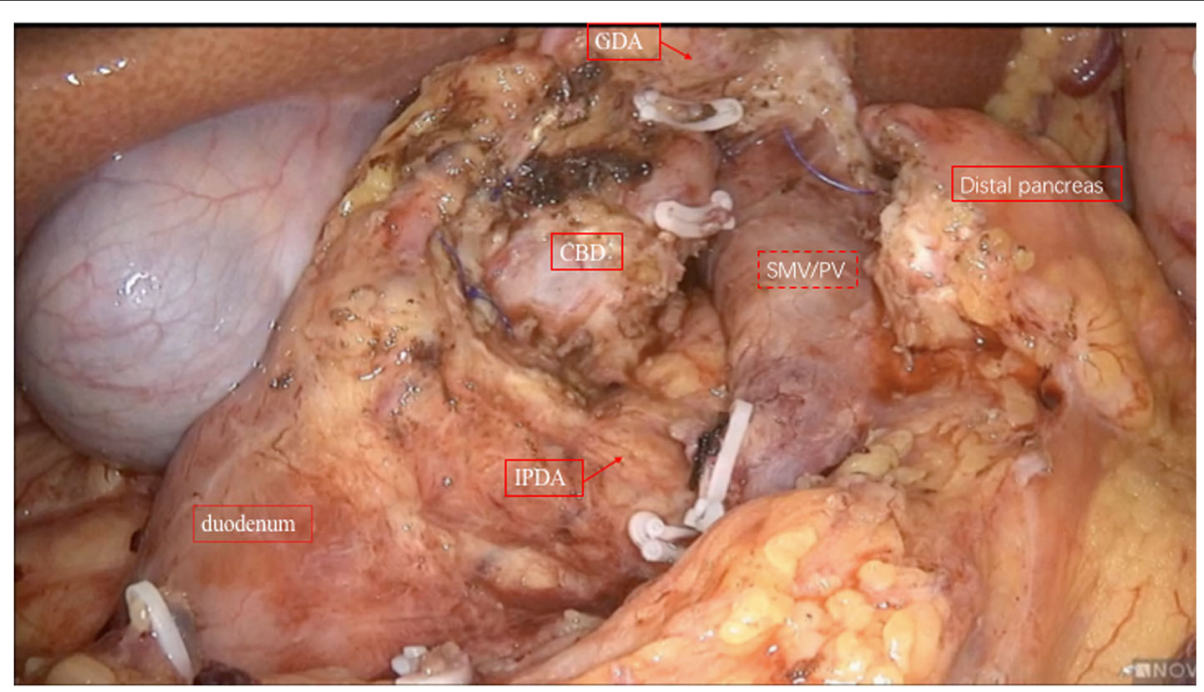

Fig. 4 The complete laparoscopic Beger procedure of while preserving the duodenum, biliary tract and pancreatic duodenal arterial arcades 


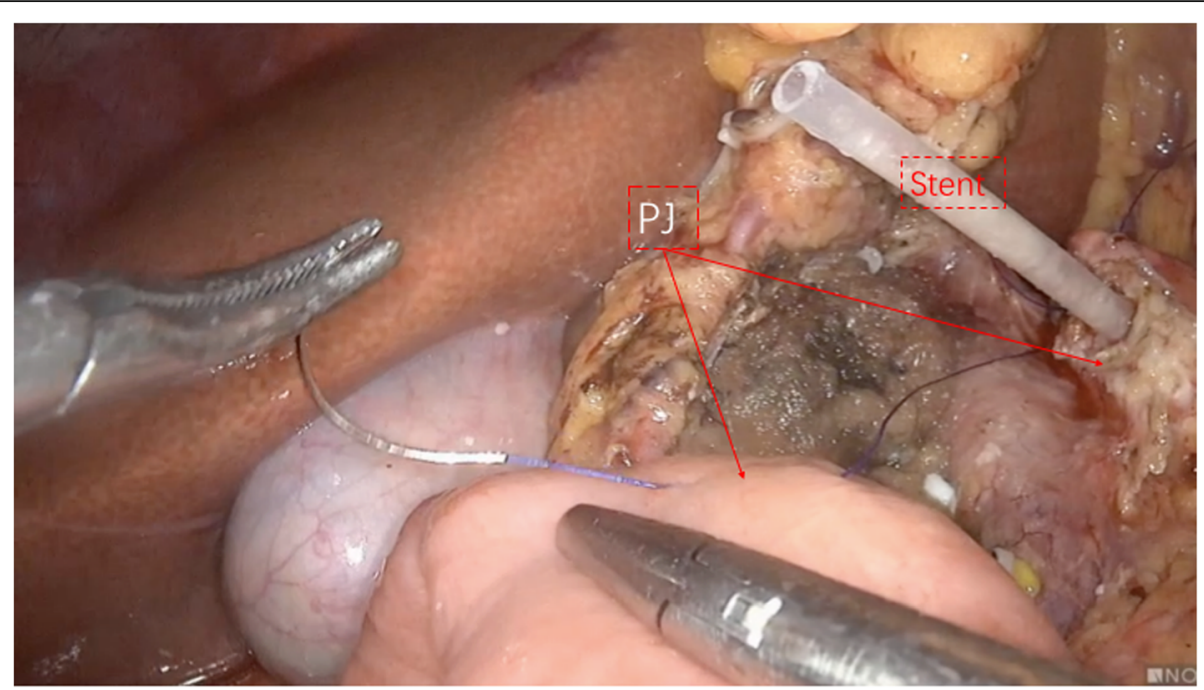

Fig. 5 Bing's Duct-to-mucosa pancreaticojejunostomy

postoperative pain relief and improved quality of life with the Beger procedure compared with PD [20]. After a 15-year long-term follow-up, Kai Bachmann found equal pain control but better quality of life for the Frey procedure had versus PD in the treatment of CP [21]. Diener [22] carried out a multicentre randomized controlled trial that included $250 \mathrm{CP}$ patients with 24 months of follow-up after surgery, and the result showed that the quality of life was equal between partial PD and DPPHR. Although some doubt remains, DPPHR (including the Beger procedure) seems to be the operation of choice for patients with CP [15].

No differences are seen for DPPHR versus PD regarding postoperative pain relief, overall mortality and morbidity up to two years of follow-up [22]. A Dutch study including 146 patients with CP who underwent surgery reported pain relief in $68 \%$ of patients [23], and a 2015 meta-analysis of 23 studies reported that pain relief was achieved in $89 \%$ of patients who underwent the Frey procedure [24]. Our study showed a $100 \%$ pain-free rate. The incidence of pancreatic fistula may be higher in DPPHR than that in PD due to a pancreaticojejunostomy and a large surface of pancreatic incision on the duodenal side. In a system review, Beger et al. reported that the incidence of grade $\mathrm{B} / \mathrm{C}$ pancreatic fistula was $13.6 \%$ after DPPHR [25]. The incidence of grade B pancreatic fistula was $20 \%$ in our study, and the small sample size may have led to a higher statistical rate. Bile leakage is another common complication of DPPHR. Cao J et al. reported that the incidence of biliary fistula was $16.7 \%$ after laparoscopic DPPHR [26]. No patient in our study developed grade C pancreatic fistula, biliary fistula, gastroparesis, duodenal necrosis, or abdominal bleeding.

Overall, it is rather technically challenging to perform the Beger procedure laparoscopically, especially for $\mathrm{CP}$. There are only a few case reports of the minimallyl invasive Beger procedure for $\mathrm{CP}$ in the literature $[9,10]$. Here, we elaborated the surgical techniques and outcomes of the operation in detail. Although these results need validation with studies enrolling a greater number of patients and a comparison with open surgery, our study shows that the laparoscopic Beger procedure is feasible and safe with good short-term results and some potential benefits in selected patients with chronic pancreatitis.

Table 3 Operative and postoperative outcomes

\begin{tabular}{llllll}
\hline Patient & Operative Time $(\mathrm{min})$ & Blood loss $(\mathrm{ml})$ & Hospital Stay $(\mathrm{d})$ & Reoperation & Complications \\
\hline 1 & 150 & 100 & 14 & 0 & 0 \\
2 & 275 & 300 & 11 & 0 & 0 \\
3 & 230 & 200 & 34 & 0 & Grade B pancreatic fistula \\
4 & 300 & 200 & 10 & Laparoscopic re-anastomosis for & 0 \\
5 & 305 & 200 & 9 & jejunal anastomotic bleeding & 0 \\
Total & $275(190-302.5)^{\mathrm{a}}$ & $200(150-250)^{\mathrm{a}}$ & $11(9.5-24)^{\mathrm{a}}$ & $1(20 \%)$ & $1(20 \%)$ \\
\hline
\end{tabular}

adata shown as median (quartile) 


\section{Abbreviations}

CP: Chronic pancreatitis; DPPHR: Duodenum preserving pancreatic head resection; PD: Pancreaticoduodenectomy; CBD: Common bile duct; GDA: Gastro-duodenal artery; ASPDA: Anterior superior pancreatic duodenal artery; PSPDA: Posterior superior pancreatic duodenal artery; IPDA: Inferior pancreaticoduodenal artery; SMV: Superior mesenteric vein; PV: Portal vein; PJ: Pancreaticojejunostomy

\section{Acknowledgements}

No acknowledgements to be declared.

\section{Authors' contributions}

HC wrote the study; QC and XW collected and analyzed the data. BP performed the surgery. All authors read and approved the final manuscript

\section{Funding}

Not applicable.

\section{Availability of data and materials}

The data supporting the findings of this study are available within the article.

\section{Ethics approval and consent to participate}

The consents to participate were obtained from all patients, which was approved by the Ethics Committee of Sichuan University.

\section{Consent for publication}

Written informed consent was obtained from the patients for publication of this Case Report and any accompanying images and videos. A copy of the written consent is available for review by the Editor of this journal.

\section{Competing interests}

The authors declare that they have no competing interests.

\section{Author details}

'Department of Pancreatic Surgery, West China Hospital, Sichuan University, No. 37, Guo Xue Xiang, Chengdu 610041, Sichuan, China. ${ }^{2}$ Department of Minimal Invasive Surgery, Shangjin Nanfu Hosptial, Chengdu, China.

Received: 27 February 2020 Accepted: 16 April 2020

Published online: 29 April 2020

\section{References}

1. Dominguez-Munoz JE, Drewes AM, Lindkvist B, Ewald N, Czako L, Rosendahl J, Lohr JM, HaPan EUUEGWG. Recommendations from the united European gastroenterology evidence-based guidelines for the diagnosis and therapy of chronic pancreatitis. Pancreatology. 2018;18(8):847-54.

2. Singh VK, Yadav D, Garg PK. Diagnosis and Management of Chronic Pancreatitis: a review. JAMA. 2019;322(24):2422-34.

3. Cahen DL, Gouma DJ, Laramee P, Nio Y, Rauws EA, Boermeester MA, Busch OR, Fockens P, Kuipers EJ, Pereira SP, et al. Long-term outcomes of endoscopic vs surgical drainage of the pancreatic duct in patients with chronic pancreatitis. Gastroenterology. 2011;141(5):1690-5.

4. Cahen DL, Gouma DJ, Nio Y, Rauws EA, Boermeester MA, Busch OR, Stoker J, Lameris JS, Dijkgraaf MG, Huibregtse K, et al. Endoscopic versus surgical drainage of the pancreatic duct in chronic pancreatitis. N Engl J Med. 2007; 356(7):676-84

5. Dite $P$, Ruzicka M, Zboril V, Novotny I. A prospective, randomized trial comparing endoscopic and surgical therapy for chronic pancreatitis. Endoscopy. 2003;35(7):553-8.

6. Majumder S, Chari ST. Chronic pancreatitis. Lancet. 2016;387(10031):1957-66.

7. Beger HG, Buchler M, Bittner RR, Oettinger W, Roscher R. Duodenumpreserving resection of the head of the pancreas in severe chronic pancreatitis. Early and late results. Ann Surg. 1989;209(3):273-8.

8. Diener MK, Rahbari NN, Fischer L, Antes G, Buchler MW, Seiler CM. Duodenum-preserving pancreatic head resection versus pancreatoduodenectomy for surgical treatment of chronic pancreatitis: a systematic review and meta-analysis. Ann Surg. 2008:247(6):950-61.

9. Peng $C-H$, Shen B-Y, Deng X-X, Zhan Q, Han B, Li H-W. Early experience for the robotic duodenum-preserving pancreatic head resection. World J Surg. 2012;36(5):1136-41.
10. Khaled YS, Ammori BJ. Laparoscopic lateral pancreaticojejunostomy and laparoscopic Berne modification of Beger procedure for the treatment of chronic pancreatitis: the first UK experience. Surg Laparosc Endosc Percutan Tech. 2014:24(5):e178-82.

11. Bloechle C, Izbicki JR, Knoefel WT, Kuechler T, Broelsch CE. Quality of life in chronic pancreatitis--results after duodenum-preserving resection of the head of the pancreas. Pancreas. 1995;11(1):77-85.

12. Cai Y, Luo H, Li Y, Gao P, Peng B. A novel technique of pancreaticojejunostomy for laparoscopic pancreaticoduodenectomy. Surg Endosc. 2019:33(5):1572-7.

13. Bassi C, Marchegiani G, Dervenis C, Sarr M, Abu Hilal M, Adham M, Allen P, Andersson R, Asbun HJ, Besselink MG, et al. The 2016 update of the international study group (ISGPS) definition and grading of postoperative pancreatic fistula: 11 years after. Surgery. 2017;161(3):584-91.

14. Machicado JD, Amann ST, Anderson MA, Abberbock J, Sherman S, Conwell DL, Cote GA, Singh VK, Lewis MD, Alkaade S, et al. Quality of life in chronic pancreatitis is determined by constant pain, disability/unemployment, current smoking, and associated co-morbidities. Am J Gastroenterol. 2017; 112(4):633-42.

15. Kempeneers MA, Issa Y, Ali UA, Baron RD, Besselink MG, Buchler M, Erkan M, Fernandez-Del Castillo C, Isaji S, Izbicki J, et al. International consensus guidelines for surgery and the timing of intervention in chronic pancreatitis. Pancreatology. 2020;20(2):149-57.

16. Anderson MA, Akshintala V, Albers KM, Amann ST, Belfer I, Brand R, Chari S, Cote G, Davis BM, Frulloni L, et al. Mechanism, assessment and management of pain in chronic pancreatitis: recommendations of a multidisciplinary study group. Pancreatology. 2016;16(1):83-94.

17. Ceppa EP, Pappas TN. Modified puestow lateral pancreaticojejunostomy. J Gastrointest Surg. 2009;13(5):1004-8.

18. Frey CF, Smith GJ. Description and rationale of a new operation for chronic pancreatitis. Pancreas. 1987;2(6):701-7.

19. Gloor B, Friess H, Uhl W, Buchler MW. A modified technique of the Beger and Frey procedure in patients with chronic pancreatitis. Dig Surg. 2001; 18(1):21-5.

20. Yin Z, Sun J, Yin D, Wang J. Surgical treatment strategies in chronic pancreatitis: a meta-analysis. Arch Surg. 2012;147(10):961-8.

21. Bachmann K, Tomkoetter L, Kutup A, Erbes J, Vashist Y, Mann O, Bockhorn $\mathrm{M}$, Izbicki JR. Is the Whipple procedure harmful for long-term outcome in treatment of chronic pancreatitis? 15-years follow-up comparing the outcome after pylorus-preserving Pancreatoduodenectomy and Frey procedure in chronic pancreatitis. Ann Surg. 2013;258(5):815-21.

22. Diener MK, Hüttner FJ, Kieser $M$, Knebel $P$, Dörr-Harim C, Distler M, Grützmann R, Wittel UA, Schirren R, Hau H-M, et al. Partial pancreatoduodenectomy versus duodenum-preserving pancreatic head resection in chronic pancreatitis: the multicentre, randomised, controlled, double-blind ChroPac trial. Lancet. 2017:390(10099):1027-37.

23. van der Gaag NA, van Gulik TM, Busch OR, Sprangers MA, Bruno MJ, Zevenbergen C, Gouma DJ, Boermeester MA. Functional and medical outcomes after tailored surgery for pain due to chronic pancreatitis. Ann Surg. 2012;255(4):763-70.

24. Zhou Y, Shi B, Wu L, Wu X, Li Y. Frey procedure for chronic pancreatitis: evidence-based assessment of short- and long-term results in comparison to pancreatoduodenectomy and Beger procedure: a meta-analysis. Pancreatology. 2015;15(4):372-9.

25. Beger HG, Mayer B, Rau BM. Parenchyma-sparing, limited pancreatic head resection for benign tumors and low-risk Periampullary cancer--a systematic review. J Gastrointest Surg. 2016:20(1):206-17.

26. Cao J, Li GL, Wei JX, Yang WB, Shang CZ, Chen YJ, Lau WY, Min J. Laparoscopic duodenum-preserving total pancreatic head resection: a novel surgical approach for benign or low-grade malignant tumors. Surg Endosc. 2019:33(2):633-8.

\section{Publisher's Note}

Springer Nature remains neutral with regard to jurisdictional claims in published maps and institutional affiliations. 